\title{
Rings in the esophagus are not always eosinophilic esophagitis: Case series of ring forming lymphocytic esophagitis and review of the literature
}

\section{(ㄷ) (i) $(-)$}

Authors

Julia L. Pleet ${ }^{1}$, Sofia Taboada ${ }^{2}$, Arvind Rishi ${ }^{2}$, Perry J. Milman ${ }^{3}$, Arvind J. Trindade ${ }^{1}$

Institutions

1 Department of Medicine, Division of Gastroenterology, Hofstra Northwell School of Medicine, Long Island Jewish Medical Center, New Hyde Park, New York, United States

2 Department of Pathology, Hofstra Northwell School of Medicine, Long Island Jewish Medical Center, New Hyde Park, New York, United States

3 Lake Success Gastroenterology, Lake Success, New York, United States

submitted 11.10.2016

accepted after revision 15.2.2017

\author{
Bibliography \\ DOI https://doi.org/10.1055/s-0043-106579 | \\ Endoscopy International Open 2017; 05: E484-E488 \\ (c) Georg Thieme Verlag KG Stuttgart · New York \\ ISSN 2364-3722
}

\section{Corresponding author}

Arvind J. Trindade, MD, Division of Gastroenterology, Long Island Jewish Medical Center, Hofstra Northwell School of Medicine, Northwell Health System, 270-05 76th, Avenue,
New Hyde Park, NY 11040

Fax: +1-718-470-5509

atrindade@northwell.edu

\section{ABSTRACT}

Background and study aims Lymphocytic esophagitis (LyE) is a form of chronic esophagitis characterized by edema and lymphocytic infiltration of the epithelial peripapillary fields, without eosinophils. Its significance is unclear, as it was previously thought to have little clinical impact. More recent literature, however, describes a paradigm shift suggesting a distinct entity. We report on 3 patients with dysphagia who were found to have esophageal rings on endoscopy. Histology was consistent with LyE. Additional features reported in this cohort included an esophageal web, esophageal pseudodiverticula and esophageal erythema. We also report a current literature review of the topic. The literature review reported here includes another 37 patients with LyE and rings, for a total of 40 patients. Patients with LyE may present with esophageal rings and other findings. LyE should be considered in the differential diagnosis of esophageal rings.

\section{Introduction}

The presence of esophageal rings used to be a strong indicator for eosinophilic esophagitis (EoE) [1]. In 2006, however, Rubio and colleagues described 20 unique cases of chronic esophagitis postulating a new entity, lymphocytic esophagitis (LyE) [2]. Subsequent studies of LyE have noted endoscopic features similar to EoE, including esophageal rings, esophagitis, esophageal stricture, erythema, nodularity, plaques, furrows and webs [36]. Histology of LyE is characterized by a chronic inflammation of the mid and distal esophagus with epithelial lymphocytic infiltration, particularly involving the peripapillary fields, distinct from other forms of chronic esophagitis where lymphocytes predominate in the interpapillary fields [2]. The relative absence of granulocytes is a notable feature of this disease entity.
Since its description, there have been numerous publications supporting this condition as a distinct clinical entity [310]. Few have commented on the presence of esophageal rings. Here we aim to contribute to the limited literature by describing three cases of lymphocytic esophagitis with esophageal rings.

\section{Patients and methods}

This is a retrospective report of 3 consecutive patients with esophageal rings on endoscopy diagnosed with lymphocytic esophagitis between October 2015 and August 2016 at Northwell Health System, New Hyde Park, New York, United States. Institutional Review Board approval was obtained to abstract patient information from the medical chart. Informed consent 


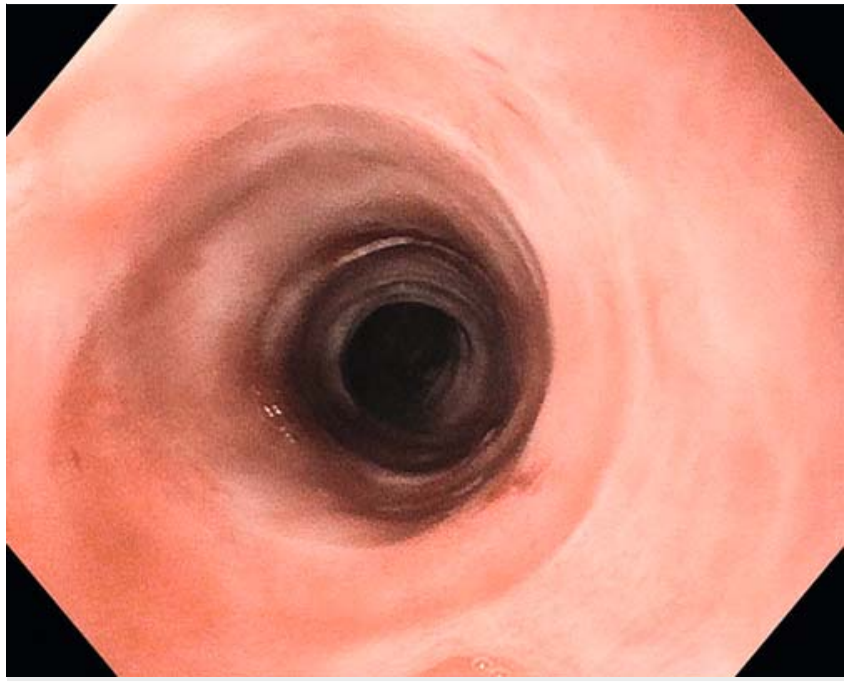

- Fig. 1 Endoscopy from a patient with lymphocytic esophagitis showing a narrowed esophagus with rings.

was obtained for each procedure. Charts were reviewed and clinical data was abstracted.

\section{Case Reports}

\section{Patient 1}

An 81-year-old male presented with 6 months of dysphagia to solid food, episodes of regurgitation, and 18-lb weight loss. Medical and surgical history was significant for bladder cancer status post-bladder resection and ileal conduit. Medications included rabeprazole and multivitamins. There were no environmental or drug allergies. The patient quit smoking 30 years prior, with a 15-pack-year history. He reported daily alcohol intake ( 1 - 2 drinks/day). The patient underwent an upper endoscopy, which showed esophageal concentric rings ( $>$ Fig.1), a proximal web, pseudodiverticula and a distal Schatzki's ring. Histology showed squamous epithelium with reactive changes infiltrated by 70 lymphocytes per high power field (400-fold magnification), particularly in the peripapillary regions. No intraepithelial eosinophils, neutrophils, or other granulocytes were identified ( $\triangleright$ Fig.2). Gastric and duodenal biopsies were without lymphocytic involvement. Endoscopy 1 year later demonstrated the same endoscopic and histologic findings. The patient required endoscopic dilation of the esophageal web during both endoscopies and was started on oral fluticasone 220 micrograms twice daily with improvement of symptoms including resolution of his symptoms of dysphagia to solid foods and no further episodes of regurgitation over the subsequent 6month follow-up.

\section{Patient 2}

A 67-year-old female presented with complaints of a globus sensation for several months. She denied weight loss, regurgitation, vomiting, chest or abdominal pain. Medical, surgical, and family history were noncontributory including no autoimmune diseases. Medications included simvastatin, levothyrox-

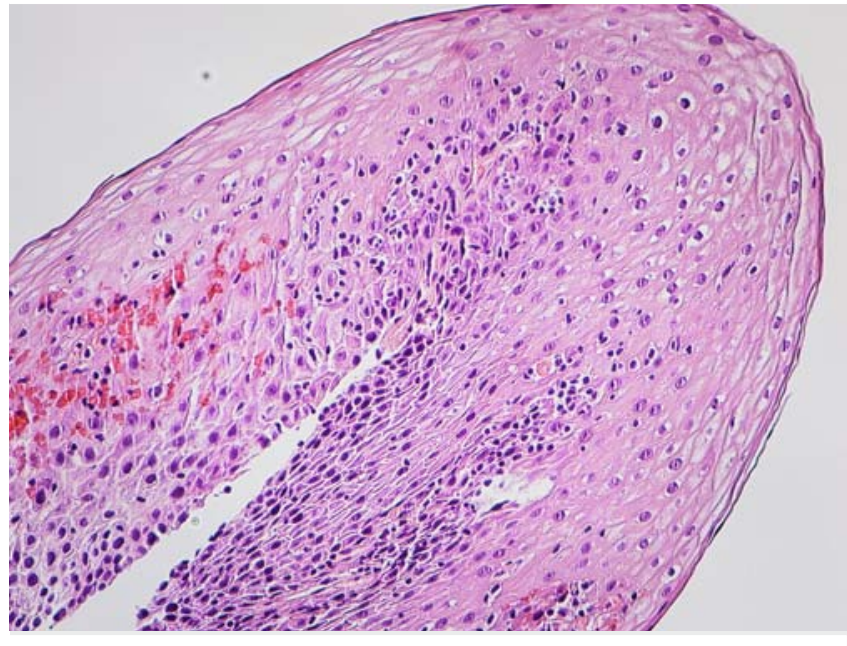

- Fig. 2 Histology from the patient in $\mathbf{~ F i g . ~} 1$ that showed squamous epithelium with reactive changes, infiltrated by intraepithelial lymphocytes, particularly in the peripapillary regions. No intraepithelial eosinophils or neutrophils were identified.

ine, and fexofenadine. She noted environmental allergies, including grass, ragweed and tree pollen, and denied drug allergies. The patient reported a distant smoking history and denied alcohol intake. Upper endoscopy was notable for concentric rings in the mid-esophagus ( $\mathbf{F i g . 3}$ ) and evidence of distal esophageal erythema, just proximal to a $3-\mathrm{cm}$ hiatal hernia. Pathology of the middle and distal esophagus demonstrated 48 lymphocytes per high power field concentrated around the squamous papillae, without granulocytes. The patient was started on a proton pump inhibitor with near complete resolution of her globus sensation at 1 year follow up.

\section{Patient 3}

A 53-year-old male with a history of Crohn's disease managed on adalimumab, budesonide and mesalamine presented with 1 year of dysphagia to solid foods. Medical history was significant for asthma requiring albuterol and a small bowel resection. He denied environmental or drug allergies. The patient was a former smoker. Endoscopy demonstrated a distal esophageal ring ( $\triangleright$ Fig.4). Histology showed absence of granulocytes and presence of 75 lymphocytes per high power field, with highest concentrations in the peripapillary region of the esophageal squamous mucosa, consistent with lymphocytic esophagitis. An esophageal motility study was consistent with mechanical obstruction in the distal esophagus. The patient underwent a repeat endoscopy with balloon dilation of the lower esophageal ring with immediate improvement in his complaints of dysphagia to solids. The patient was started on oral fluticasone 220 mcg twice daily with maintenance in resolution of symptoms at 5-month follow-up.

\section{Summary of case series}

All 3 cases reported here show esophageal rings, which were previously thought to be suggestive of EoE. However, rings can be associated with LyE and cause symptoms of dysphagia. 


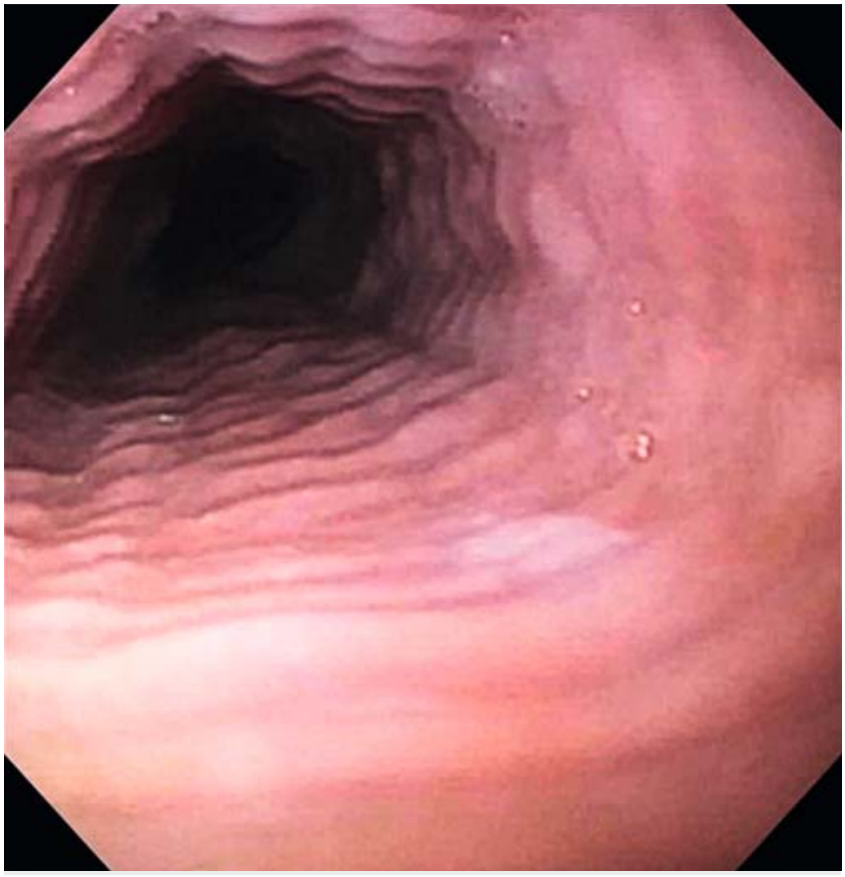

- Fig. 3 A patient with lymphocytic esophagitis with concentric rings on endoscopy.

Other features reported in this series were esophageal erythema, pseudodiverticula and a web. Successful endoscopic dilation in 2 of the cases demonstrates its safety in this patient population. Two of the patients in this series were prescribed oral fluticasone, a medication prescribed in EoE. Although the benefit is extrapolated from EoE, both patients responded to this treatment.

\section{Discussion}

Clinical findings for LyE are non-specific. The overall pattern of inflammation, distribution of lymphocytes within the squamous epithelium, and clinical presentation are important in making a diagnosis. LyE is a pathologic diagnosis characterized as having the following: 1) a large number of lymphocytes in the peripapillary region of the esophageal squamous epithelium; 2) frequent absence of granulocytes (i.e. eosinophils, neutrophils) [2]; and 3) marked intracellular edema/spongiosis $[3,4]$. In contrast, biopsies in patients with gastroesophageal reflux disease (GERD) demonstrate minimal, if any, reactive histologic changes. There has been no association identified between LyE and lymphocytic infiltration at other sites in the gastrointestinal tract [3].

The lymphocytes identified on biopsy of patients with LyE expressed CD3, CD4, CD8 and rarely granzyme B, without T-cell intracytoplasmic antigen 1 [2]. No granulocytes were present in $60 \%$ of biopsies meeting diagnostic criteria for lymphocytic esophagitis, and only occasional granulocytes were seen in the remaining $40 \%$. In contrast, many granulocytes were present in the other forms of esophagitis, including grade 2 and 3 gastroesophageal reflux and Candida albicans esophagitis [2].

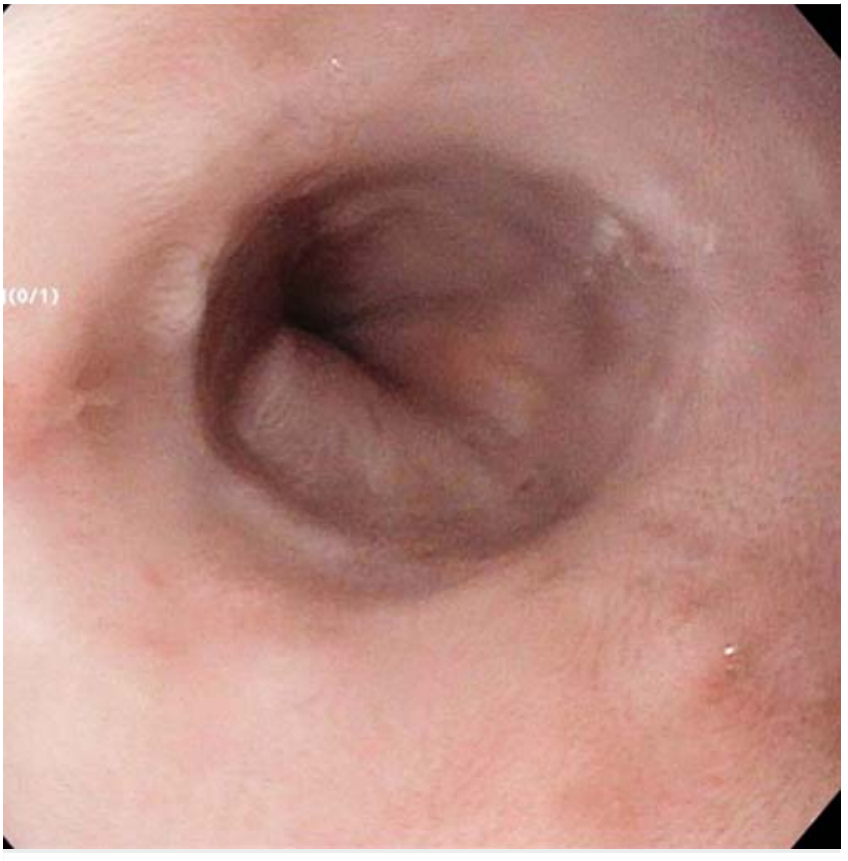

- Fig.4 A patient with lymphocytic esophagitis with a distal esophagus ring on endoscopy.

In a study of 119 cases of LyE, patients presented with similar symptoms as patients with EoE, most commonly dysphagia (LyE: $53 \%$ vs. EoE: $63 \%$ ) [4]. Across 4 studies of patients with LyE, complaints of dysphagia and heartburn were noted in 43 $70 \%$ and $18.5-47 \%$ of patients respectively [3-6]. Additional symptoms include odynophagia, abdominal pain, chest pain, nausea, vomiting, regurgitation, and heartburn ( $\triangleright$ Table 1). Notable complications of LyE include food impactions [7].

Overall, LyE was detected in $\sim 0.1 \%$, or 1 in 1000 , of all patients who underwent esophageal biopsies for any cause [4]. LyE predominantly affects older women (60\%) with a median age of 63. In contrast, EoE tends to affect younger men (66\%) with a median age of 43 [4]. The majority of LyE patients are white (86\%) [5]. When compared to patients with normal esophageal biopsies, GERD and EoE, patients with LyE were more likely to use tobacco, had comparable rates of drug and food allergies, and were less likely to have allergic rhinitis [6].

Patients with LyE can have a variety of endoscopic findings ( $\triangleright$ Table 1 ). Across 4 studies, the appearance of a normal esophagus in LyE ranged from $18 \%$ to $31 \%$ [3-6]. Esophageal rings were present in $19.8 \%$ of patients (vs. $18.8 \%$ of patients with EoE) [5]. In contrast to EoE, patients with LyE had fewer esophageal strictures (8.6\% vs. $16.3 \%$ ) [5], however the incidence of strictures in LyE ranged from $8.6 \%$ to $37 \%$ [4-6]. Overall, based on the endoscopic appearance of the esophagus, EoE was suspected by physicians in one third of LyE cases [4], demonstrating that these clinically distinct entities have overlapping features.

Thirty-seven cases of LyE with esophageal rings have been reported in the literature to date. With this case series, there are now 40 reported cases. There is no identifiable unifying feature that would allow postulation of an associated condition or 
- Table 1 Symptoms and endoscopic findings in patients with lymphocytic esophagitis across 4 studies.

\begin{tabular}{|c|c|c|c|c|}
\hline & Purdy et al. [3] (\%) & Haque et al. [4] (\%) & Cohen et al. [5] (\%) & Pasricha et al. [6] (\%) \\
\hline \multicolumn{5}{|l|}{ Clinical manifestations } \\
\hline Dysphagia & 43 & 52.9 & 66.7 & 70 \\
\hline Heartburn/reflux & 26 & 18.5 & 46.9 & 26 \\
\hline Abdominal/chest pain & - & - & 44.4 & - \\
\hline Abdominal pain & - & - & - & 15 \\
\hline Chest pain & - & - & - & 19 \\
\hline Nausea/vomiting & - & - & 29.6 & 19 \\
\hline Odynophagia & - & - & 12.3 & 4 \\
\hline All esophageal symptoms & 57 & - & - & - \\
\hline \multicolumn{5}{|l|}{ Endoscopic impressions } \\
\hline Normal & 31 & 22.6 & 29.6 & 18 \\
\hline Esophagitis & 24 & 18.5 & 16.0 & 33 \\
\hline Eosinophilic esophagitis & - & 33.6 & - & - \\
\hline Esophageal rings & 12 & - & 19.8 & 26 \\
\hline Stricture & - & 10.1 & 8.6 & 37 \\
\hline Motility disorder & - & 5.0 & - & - \\
\hline Schatzki's ring & - & 2.5 & - & - \\
\hline Candida & - & 1.6 & - & 15 \\
\hline Achalasia & - & 0.8 & - & - \\
\hline Hiatal hernia & 10 & - & - & 26 \\
\hline Narrow caliber & - & - & - & 44 \\
\hline
\end{tabular}

- Table 2 Summary of literature on lymphocytic esophagitis with esophageal rings

\begin{tabular}{|c|c|c|c|c|c|c|c|c|c|}
\hline & $\begin{array}{l}\text { Purdy } \\
\text { et al. [3] }\end{array}$ & $\begin{array}{l}\text { Haque } \\
\text { et al. [4] }\end{array}$ & $\begin{array}{l}\text { Cohen } \\
\text { et al. [5] }\end{array}$ & $\begin{array}{l}\text { Pasricha } \\
\text { et al. [6] }\end{array}$ & $\begin{array}{l}\text { Man- } \\
\text { daliya } \\
\text { et al. } \\
\text { [7] }\end{array}$ & $\begin{array}{l}\text { Kasir- } \\
\text { ye et } \\
\text { al. [8] }\end{array}$ & $\begin{array}{l}\text { Nie- } \\
\text { wiar- } \\
\text { owski } \\
\text { et al. } \\
\text { [9] }\end{array}$ & $\begin{array}{l}\text { Zhang } \\
\text { et al. } \\
{[10]}\end{array}$ & Pleet et al. \\
\hline \# patients with LyE, $n$ & 42 & 119 & 81 & 27 & 1 & 1 & 1 & 1 & 3 \\
\hline $\begin{array}{l}\text { \# patients with LyE and } \\
\text { esophageal rings, } n\end{array}$ & $5(12 \%)$ & $5(4 \%)$ & $16(20 \%)$ & $7(26 \%)$ & 1 & 1 & 1 & 1 & $3(100 \%)$ \\
\hline Men, $n$ & - & 47 (40\%) & 37 (46\%) & $10(37 \%)$ & 1 & 0 & 0 & 0 & $2(67 \%)$ \\
\hline Age, years & 45 (median) & 62 (median) & 51 (median) & 56 (mean) & 74 & 60 & 82 & 66 & 67 (median) \\
\hline Caucasian, $n$ & - & - & $69(85 \%)$ & $16(59 \%)$ & - & - & - & - & $3(100 \%)$ \\
\hline Tobacco use, $n$ & - & - & $24(30 \%)$ & $13(48 \%)$ & - & - & - & 1 & $3(100 \%)$ \\
\hline
\end{tabular}

patient characteristic ( $\triangleright$ Table 2 ). Two of the 3 patients in this case series underwent balloon dilation of their esophageal rings with symptomatic improvement in their dysphagia.
Treatment with proton pump inhibitors, alterations in eating habits, and topical steroids are of unknown benefit. Anecdotal evidence supporting the use of proton pump inhibitors is conflicting. Currently there is insufficient evidence to recommend 
lifestyle changes or medical therapy for LyE. Patients with LyE and webs, rings or strictures can benefit from mechanical dilation, though symptoms can recur.

The clinical course of LyE is largely unknown. In one study, almost $90 \%$ of patients were still living 3 years after diagnosis and reported good quality of life at follow up [5]. Repeat upper endoscopy on patients with previously diagnosed LyE demonstrated persistent LyE in $41 \%$ of cases, with the remaining cases showing normal or alternative diagnoses [5]. Nearly $60 \%$ of this cohort of LyE patients reported improvement in initial symptoms, largely attributed to escalation of medical management (70.6\% of cases), usually with a proton pump inhibitor [5].

Since it was first described in 2006, the diagnosis of LyE has risen drastically [5]. While it's clinical presentation may overlap with other forms of chronic esophagitis, particularly EoE, it is histologically distinct. As our case series shows, patients with LyE may present with esophageal rings. Further research is needed to determine the cause, clinical course and effective treatment options for this disease entity.

\section{Competing interests}

None

\section{References}

[1] Dellon ES, Rusin S, Gebhart JH et al. A Clinical Prediction Tool Identifies Cases of Eosinophilic Esophagitis Without Endoscopic Biopsy: A Prospective Study. Am J Gastroenterol 2015; 110: 1347-1354

[2] Rubio CA, Sjödahl K, Lagergren J. Lymphocytic esophagitis: a histologic subset of chronic esophagitis. Am J Clin Pathol 2006; 125: 432 437

[3] Purdy JK, Appelman HD, Golembeski CP et al. Lymphocytic esophagitis: a chronic or recurring pattern of esophagitis resembling allergic contact dermatitis. Am J Clin Pathol 2008; 130: 508- 513

[4] Haque S, Genta RM. Lymphocytic oesophagitis: clinicopathological aspects of an emerging condition. Gut 2012; 61: $1108-1114$

[5] Cohen S, Saxena A, Waljee AK et al. Lymphocytic esophagitis: a diagnosis of increasing frequency. J Clin Gastroenterol 2012; 46: 828 - 832

[6] Pasricha S, Gupta A, Reed CC et al. Lymphocytic Esophagitis: An Emerging Clinicopathologic Disease Associated with Dysphagia. Dig Dis Sci 2016; 61: 2935-2941

[7] Mandaliya R, DiMarino A, Cohen S. Lymphocytic esophagitis mimicking eosinophilic esophagitis. Ann Gastroenterol 2012; 25: 355-357

[8] Kasirye Y, John A, Rall C et al. Lymphocytic esophagitis presenting as chronic dysphagia. Clin Med Res 2012; 10: 83 - 84

[9] Niewiarowski TJ, Stoll LM. Recurrent dysphagia in a patient with chronic lymphocytic esophagitis. Gastrointest Endosc 2016: DOI: 10.1016/j.gie.2016.02.016

[10] Zhang Z, Jain D, Brand M. Ringed Esophagus Secondary to Lymphocytic Esophagitis. Gastroenterol Hepatol 2016; 12: 237-239 